\title{
A Typology of Youth Participation and Empowerment for Child and Adolescent Health Promotion
}

\author{
Naima T. Wong $\cdot$ Marc A. Zimmerman • \\ Edith A. Parker
}

Published online: 12 June 2010

(c) Society for Community Research and Action 2010

\begin{abstract}
Research suggests that increasing egalitarian relations between young people and adults is optimal for healthy development; however, the empirical assessment of shared control in youth-adult partnerships is emerging, and the field still requires careful observation, identification, categorization and labeling. Thus, our objective is to offer a conceptual typology that identifies degrees of youth-adult participation while considering the development potential within each type. We use an empowerment framework, rooted in evidence-based findings, to identify five types of youth participation: (1) Vessel, (2) Symbolic, (3) Pluralistic, (4) Independent and (5) Autonomous. The typology is constructed as a heuristic device to provide researchers, practitioners and policy-makers with a common language for articulating degrees of youth participation for optimal child and adolescent health promotion.
\end{abstract}

Keywords Youth participation $\cdot$ Participatory action research · Empowerment · Youth-adult partnerships · Child and adolescent health promotion

N. T. Wong

Georgia State University, Atlanta, GA, USA

M. A. Zimmerman ( $\square)$

Department of Health Behavior and Health Education, School of Public Health, University of Michigan, 109 South Observatory,

Ann Arbor, MI 48109-2029, USA

e-mail:marcz@umich.edu

E. A. Parker

College of Public Health, Department of Community and

Behavioral Health, University of Iowa, Iowa City, IA, USA
In recent years, researchers have begun to shift from seeing youth (i.e., children and adolescents) as problems to viewing them as resources for participatory action and research. Likewise, child and adolescent health promotion is gaining recognition as a viable approach not only to preventing youth problems, but also enhancing positive development. Prior to this shift, young people were rarely asked to voice their opinions or participate in the development of research and programs designed for them. Now, studies that use participatory asset-based approaches, such as youth empowerment, are emerging in the empirical literature (e.g., Cargo et al. 2004; Foster-Fishman et al. 2005; Jennings et al. 2006; Kim et al. 1998; Wallerstein et al. 2002). The appeal of these approaches is that they both build on young people's intrinsic strengths and actively involve them in addressing issues that they themselves identify. In addition, the issues young people identify may also be community concerns; thus, the potential to influence positively both adolescent and community development can be encouraged by actively engaging with youth.

Although participatory asset-based approaches that enhance youth voice and participation are gaining recognition, the inclusion of youth contributions is often the exception rather than rule. More than half of research articles in top adolescent journals focus on problems (Furstenberg 2000) and much of the literature can be characterized as adult-centric (Bennett et al. 2003; Daiute and Fine 2003). That is, child and adolescent research and practice are largely constructed using an adult lens whereas the perspectives and real-life experiences of young people are frequently overlooked.

Despite this adult-centric bias, young people are uniquely positioned to make important contributions to research and be agents in their own personal and community development. Youth culture, for example, can evolve 
so rapidly that by the time older age groups begin to understand it, young people have already adopted something new (Willis 1990). Adults may not be able to relate, placing children and adolescents in an optimal position to determine the relevance of efforts geared towards youth.

Moreover, late childhood to early adolescence (i.e., 10-14 years old) is an opportune time to promote health and positive development. Many of the habits and health behaviors observed in adulthood begin during this stage (Millstein et al. 1993). The desire for experimentation with different behaviors increases with the need to form an identity-a major task of adolescence. An Eriksonian view suggests identity is attained by establishing a stable selfconcept through integrating past and present experiences with future notions of self (Muuss 1962/1996). This task is achieved through psychosocial reciprocity, a process of engaging with others, to resolve three psychological crisis questions: (1) Who am I?; (2) Where am I going?; and (3) Who do I want to become? Considering these developmental needs, it is critical that children and adolescents are provided with opportunities to explore these questions in an environment that encourages autonomy, yet channels curiosity in a positive direction.

One strategy for encouraging this type of environment is to foster opportunities for children and adolescents to participate in research and decisions that affect their lives. Participatory action research (PAR), in particular, is an approach that can appeal to the fresh ideas, energy and immediate outcomes that younger people seek while empowering youth to make contributions to address issues of their concern. The basic tenets of PAR include (1) collaborating with the population under study, (2) balancing power between researchers and participants during the research process through co-learning, and (3) ensuring research is translated into action (Minkler 2000). Youth participation in action research encourages healthy development for several reasons. Involving young people in decision-making with adult researchers can build skills, mastery, and competence. When decisions are made in a group, youth are exposed to different ways of thinking, problem solving, and strategizing-which strengthens cognitive and social development. The co-learning approach of PAR also supports balancing power between youth and adult researchers. Acknowledging the value that both youth and adults can contribute allows for adults to gain insight grounded in youth perspectives and youth to learn in an environment that validates their experience. The action component of PAR also aligns with young people's needs for immediate gratification. Observing the result of their contributions can build confidence, self-efficacy and self-esteem. In addition, young people who are involved in producing knowledge that impacts policy and action in their communities may develop a stronger sense of responsibility to others. Thus, youth participation has potential to promote individual and community health by satisfying developmental needs in a positive manner while also enhancing the relevance of research, policy, and practice to lived experiences of children and adolescents.

Although the contributions of children and adolescents may be an under-utilized resource, we do not suggest they should carry the full burden of promoting health for young people. Adults ought to share in this responsibility. Researchers suggest that increasing egalitarian relations between youth and adults is optimal for healthy development (Camino 2005; Fauth et al. 2007; Fogel 2004; Larson et al. 2005; Whitlock 2007). Yet few empirical assessments of shared control in formal youth-adult partnerships exist and, therefore, the field still requires careful observation, identification, categorization and labeling (Zeldin et al. $2005 \mathrm{a}, \mathrm{b})$. Thus, our objective is to offer a typology that identifies degrees of youth-adult participation. We draw from the positive youth development perspective and use an empowerment framework rooted in evidence-based findings to rationalize the structure of the typology. The typology is also designed with the intention of providing researchers, practitioners and policy-makers a common language for articulating degrees of youth participation for optimal health promotion.

\section{Participation Typologies}

Citizen participation in matters of community has long been considered an important cornerstone of community development (Arnstein 1969; Price 1990). Researchers have found that participation can take on many forms such as community involvement in block clubs, advisory boards, and neighborhood watches, and can have multiple benefits including increased civic competence, community cohesion, and neighborhood improvements (Florin and Wandersman 1990). In parallel, the benefits and promotion of participatory action research have also expanded over the past few decades (Cornwall and Jewkes 1995). A turning point in this expansion was Arnstein's (1969) classic typology that articulates levels of citizen participation.

Arnstein uses a ladder metaphor to suggest that participation can be divided into eight types of participation that fall into three major categories: (1) non-participation, (2) tokenism, and (3) citizen power. A major assumption of Arnstein's ladder is that participation types are linear, where citizen power types are preferred over non-participation types. This framework also places emphasis on participation from the participation end users viewpoint rather than those who promote participation (Cornwall 2008). Several other participation typologies using a variety of frameworks have been published since Arnstein's ladder 
(e.g., Pretty 1995; Rocha 1997; White 1996); however, they do not illustrate how participation may differ for youth who often have a minor social status in society compared to adults and, therefore, have unique developmental contexts to be considered with regard to power and control.

Figures 1, 2, and 3 illustrate three of the more widely known typologies of youth participation: Hart's (1992) Ladder of Young People's Participation, Shier's (2001) Pathways to Participation, and Treseder's Degrees of Participation (1997). Hart's typology builds upon Arnstein's ladder metaphor and adapts the framework to produce a typology that delineates a stepwise progression of participation in the context of youth and adult interactions. Similar to Arnstein's ladder, Hart's typology (see Fig. 1) includes varying degrees of non-participation and participation types organized in a linear fashion with the assumption that the highest participation type (i.e., child initiated, shared decisions with adults) is the most desirable.

Shier's typology is intended to be used in tandem with Hart's model. The typology (see Fig. 2) expands on Hart's participation types, rather than the non-participation types, to help practitioners and researchers consider three stages of commitment that can be applied at each progressive participation level: (1) openings, (2) opportunities, and (3) obligations. At each level and stage, Shier proposes key questions that can be used to probe that current level of participation or design participatory action with youth and adults.

Shier suggests that a major contribution of Hart's typology was that his model helps practitioners uncover how many activities and programs are designed at the nonparticipation levels. To shift the focus, Shier designed his
Fig. 1 Hart's (1992) ladder of young people's participation

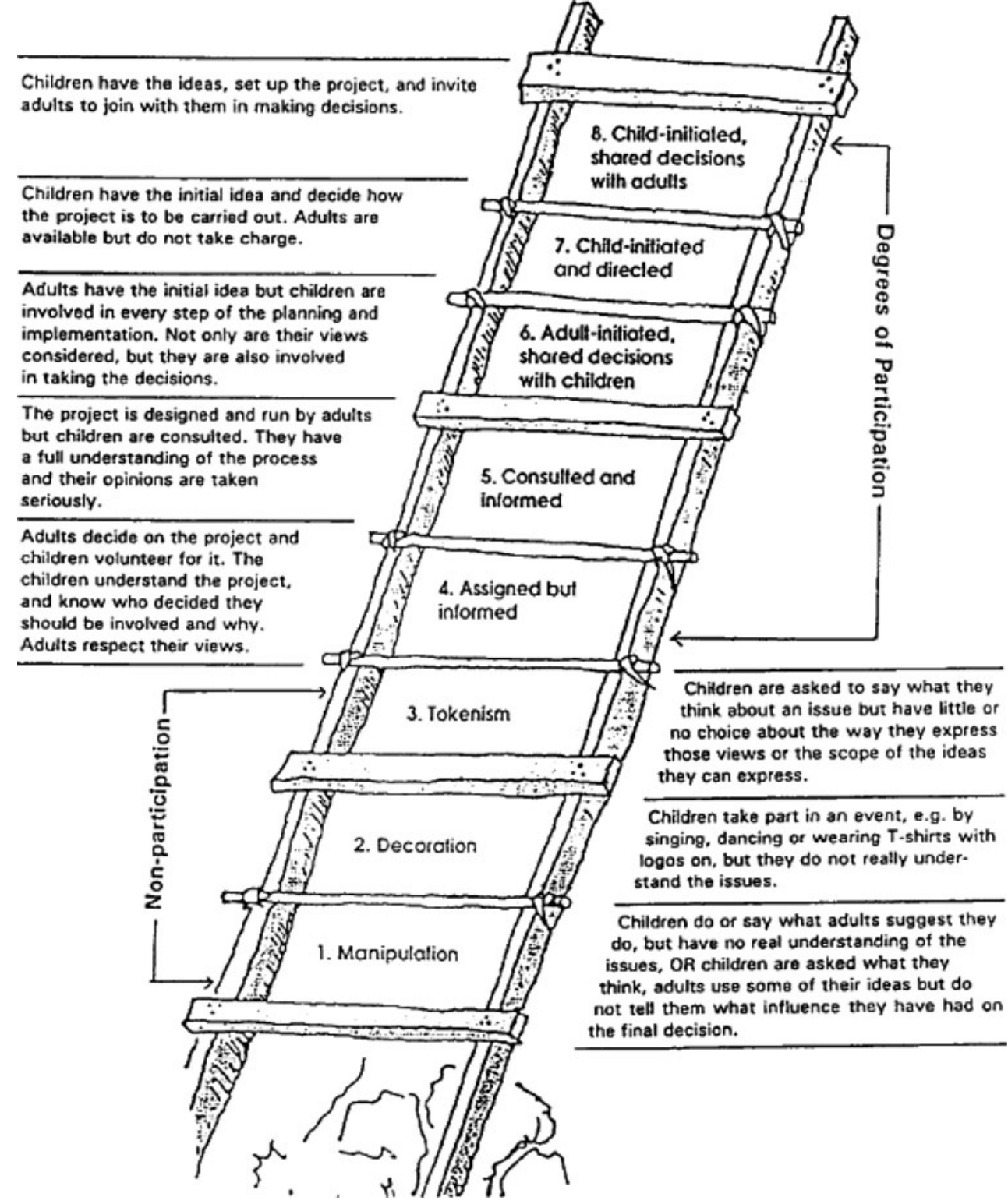



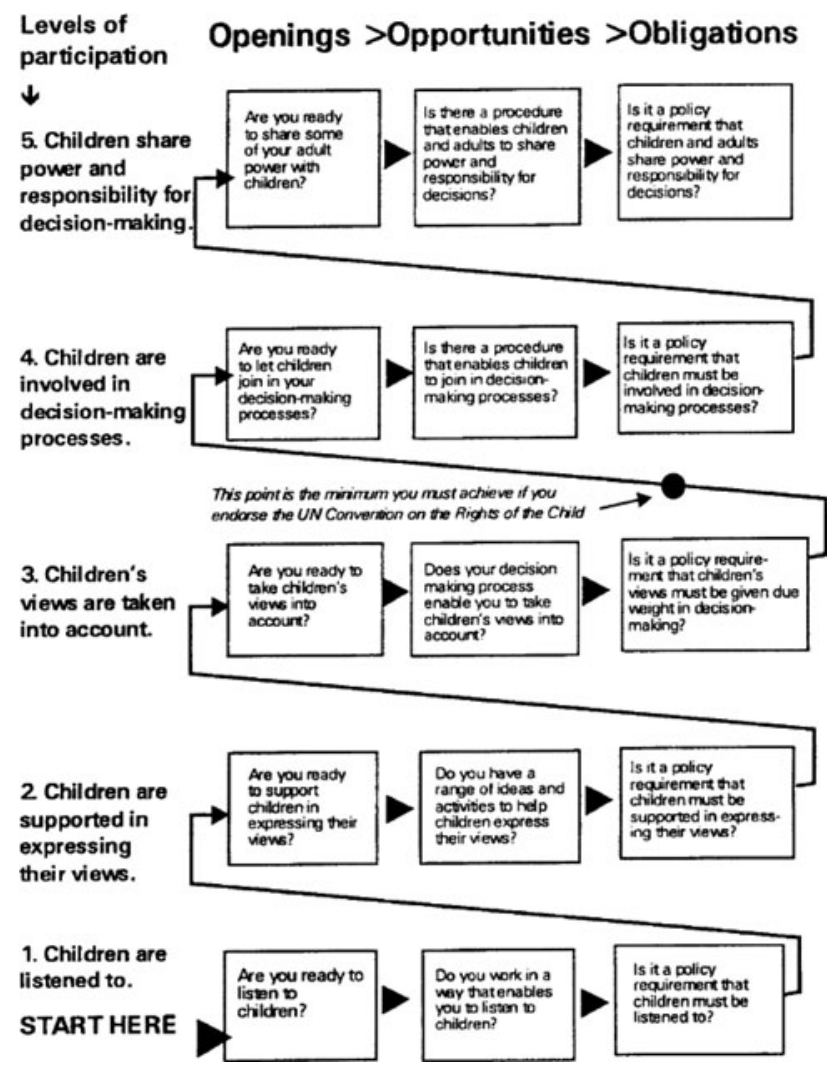

Fig. 2 Shier's (2001) pathways to participation

typology to include only the participation rungs rather than the non-participation rungs of Hart's ladder. By doing this, Shier's typology misses an opportunity to be a comprehensive model that captures the full range of youth-adult arrangements that have implications for participation. Furthermore, the questions built into Shier's typology are designed for adult responses. This adult-centric framing further perpetuates the adult position of power. Although this underlying adult bias may represent a frank reality in many cases, a reframing of youth-adult relationships in a model that focuses attention on shared youth-adult control can offer a way to conceptualize relationships that allow both young people and adults to jointly determine roles, participatory readiness, and genuine shared control in participatory action research.

Treseder's typology offers an alternative model to the linear conception of participation (see Fig. 3). He states that use of the ladder metaphor in Hart's model implies that each rung is a progressive step towards the ideal: youthdriven participation. Treseder argues that youth-driven participation may be inappropriate in some cases and that it is instead more practical to describe five types of unique yet equal forms of participation. The degrees of participation in his typology are represented in nonlinear nodes to indicate that one participation type is not more ideal than another. The five participation types included in the model are: (1) assigned, but informed, (2) adult-initiated, shared decisions with children, (3) child-initiated and directed, (4) child-initiated, shared decisions with adults, and (5) consulted and informed.

Although Hart's, Shier's, and Treseder's typologies are useful frameworks for articulating various youth participation types, none fully account for recent findings in youth-adult participation research. In Hart's model, the placement of youth-driven participation at the top of the ladder can under value the contributions and power sharing adults can lend to youth and community development. That is, the lack of adult involvement in youth-driven participation may hinder rather than encourage optimal adolescent development and empowerment. The assumption that youth-driven participation is ideal for empowerment overlooks how youth status plays out in broader social structures. In her evaluation of youth-adult partnerships, Camino (2000, 2005), for example, found that activity quality and positive development outcomes were compromised when adults were not involved. Youth may lack the skills, expertise, and connections to social capital that may be required to successfully conduct research or an activity, which can lead to frustration and unintended disempowering outcomes. Similarly, McHale et al. (2001) found that children who participated in structured activities with adults rather than unsupervised activities with peers, had improved developmental adjustment in subsequent middle school years. These findings suggest that the neutral representation of participation types in Treseder's model do not reflect the value that certain youth-adult participation arrangements can lend to the empowerment and positive development of youth. Few researchers, for example, would argue that child or youth-initiated research where children have the ideas, set up the project, and invite adults to join them is a fair balance of power sharing because adults have greater access to institutional resources. This youth initiated arrangement places a disproportionate burden on young people to assume roles they may not be able to fulfill by virtue of their minor status, limited experience with the conventions of program and research operations, and potential developmental capabilities. Therefore, shared youth-adult control in participatory research and action may be ideal for positive youth development and empowerment rather than youth-driven participation.

\section{The TYPE Pyramid: A Typology of Youth Participation and Empowerment}

The proposed typology further builds on the youth focused participation models by incorporating intergenerational linkages and considering recent research developments in youth-adult partnerships. Like Treseder, we shift from 
Fig. 3 Treseder's (1997)

degrees of participation

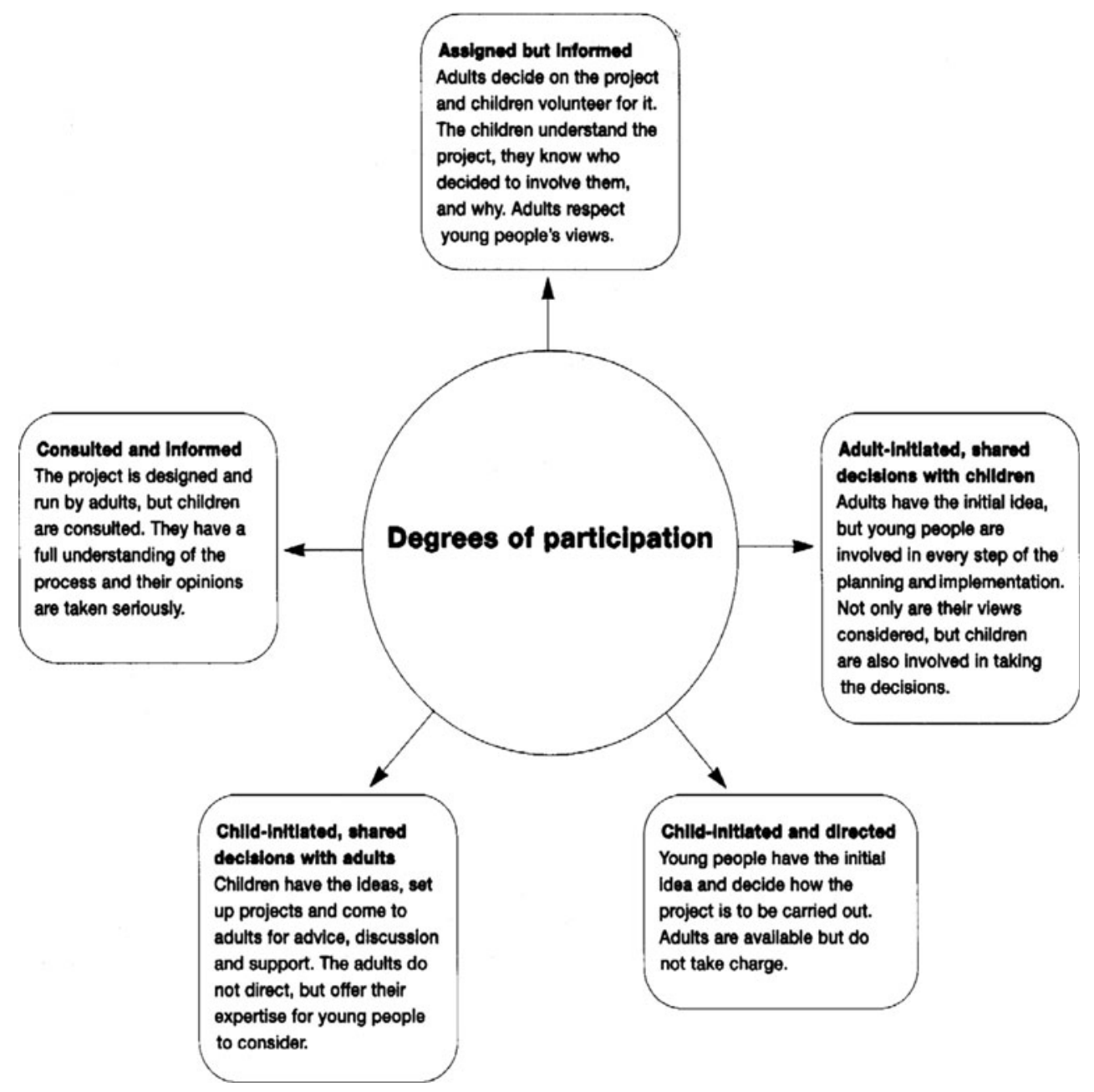

using a ladder metaphor to avoid the assumption that youth-driven participation is ideal. In contrast to Treseder, however, we use a pyramid schematic to articulate different configurations of youth-adult control that reflect optimal participation types for youth empowerment. Thus, the Typology of Youth Participation and Empowerment (TYPE) Pyramid is presented with five types of participation that delineate various levels of youth-adult involvement in an inverted V schematic: (1) Vessel, (2) Symbolic, (3) Pluralistic, (4) Independent and (5) Autonomous (see Fig. 4). The pyramid shape and arrows depicted in the model are intended to represent an evidence-based hypothesis about the degrees of empowerment and positive youth development potential for each participation type. The arrows also suggest, that although five major participation types are described in the typology, the concept of youth participation can be observed on a continuum.

\section{Characteristics of the TYPE Pyramid}

The TYPE Pyramid combines three characteristics that distinguish it from other frameworks. These characteristics are the explicit use of an empowerment theoretical framework, emphasis on both youth and adult involvement, and five participation types that articulate varying degrees of empowerment and positive youth development.

\section{Empowerment}

The TYPE Pyramid uses an empowerment framework to describe various degrees of youth-adult involvement. An empowerment framework was chosen for its conceptual emphasis on enhancing wellness, being strengths based and identifying sociopolitical influences on quality of life (Wallerstein 1992; Wallerstein and Bernstein 1988; Zimmerman 2000). Critical consciousness, also known as critical awareness and conscientization, is central to the empowerment process. The role of critical consciousness in empowerment borrows from pedagogical principles popularized by Brazilian educator, Paulo Freire (Minkler and Cox 1980; Wallerstein and Bernstein 1988; Wang and Burris 1997; Zimmerman and Warschausky 1998). Freire (1970/2003) notes that people are powerless when they are unaware of causes that shape their conditions, and that 
Fig. 4 The TYPE pyramid

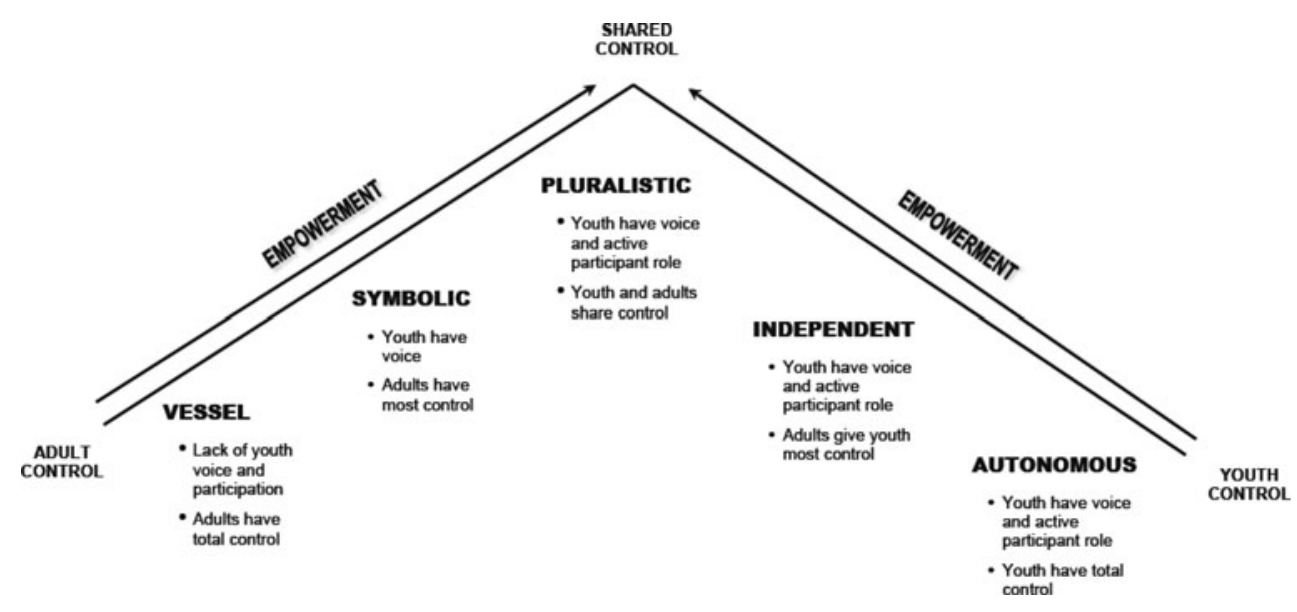

empowerment occurs through creation of a collective critical consciousness. Critical consciousness is achieved when, "people develop their power to perceive critically the way they exist in the world with which and in which they find themselves; they come to see the world not as a static reality, but as a reality in the process, in transformation" (Freire 1970/2003, p. 83, italics in original). Here Freire suggests that empowerment is derived from an awareness that is formed when individuals understand how their circumstances are shaped by not only their own behavior, but also broader social and historical forces. It is through questioning these circumstances that youth and communities can uncover their own sense of agency and become empowered.

Although critical consciousness can raise awareness about determinants of health, it is the subsequent research and behavioral action that addresses these determinants that can initiate change. Zimmerman (2000) suggests that the potential for empowerment rests on the strength of the connection between individuals, organizations and their communities. Much of this connection rests on the degree of individual and collective participation. For youth, this translates to participation in research and action with adult involvement.

\section{Youth and Adult Involvement}

Previous researchers have suggested that youth-driven participation is ideal for positive youth development and empowerment. Children and adolescents, however, cannot be expected to carry the full burden of empowering themselves and their communities. Adults ought to share in this responsibility. The uneven power dynamics that exist between youth and adults make sharing this responsibility challenging. An egalitarian approach to critical consciousness, however, may empower both youth and adults to overcome this dynamic. To achieve critical consciousness, a democratic value orientation that supports participatory co-learning is emphasized. In co-learning with youth, adults can serve as resources and collaborators-versus being the experts-by facilitating critical dialogue, awareness, and building skills towards critical consciousness in partnership with young people (Zimmerman 2000). Youth participants can be encouraged to be active collaborators and the sharing of their views contributes to critical dialogue, furthering awareness about how politics, socioeconomic position, culture and history can be fundamental in shaping individual life experience and health outcomes (Rappaport 1995; Wallerstein 1992; Zimmerman 2000). By being active collaborators, youth can also increase developmental assets such as competence, self-efficacy and sense of control by developing an awareness of and engaging with their environment (Zimmerman 1995). It is through this co-learning process with adults that youth can both become empowered and reap developmental benefits.

Children and adolescents, however, possess different needs in the empowerment process compared to adults because, given their developmental stage, youth are not afforded all the rights and responsibilities of adults. Due to these limits, young people must often depend on their elders to fulfill a variety of tasks. Adults may be needed for supervision, guidance and social support. A licensed adult, for example, must supervise a young person when they are learning how to drive a car. An adult is legally required to be present, but he or she can also provide expertise and monitor driving techniques to ensure safety. Young people may also look to adults for guidance. Research on parentchild communication, for instance, suggests that most youth have questions on a wide-range of topics they would like to ask their parents (Richardson 2004). Adults can also provide vital social support and connection to other influential adults. Young males, for example, with higher levels of parent support are at reduced risk for suicide ideation 
and violent behavior (Brookmeyer et al. 2005; Tarver et al. 2004). Researchers have also found that youth who are connected to adults with resources increase their social capital (Jarrett et al. 2005; Lerner et al. 2005; Zeldin 2004). Adults can expand youths' social networks by exposing them to other influential adults. Subsequently, young people may be able to later draw upon these networks for personal benefit such as increased job opportunities, recommendation letters and apprenticeship.

Adult involvement may be necessary, but the mere presence of adults is not sufficient for youth empowerment. The degree and quality of this involvement can affect youth development. Adults, for instance, do not necessarily need to take active roles in young peoples' lives to influence their behavior. Social learning theory suggests children and adolescents often take cues about their own behavior from adult role models (Bandura 1977). Findings in youth voice research support social learning theory by suggesting that the decisions adults make play a significant role in young people's lives. Phelan et al. (1992), for example, found that when they asked students about the school environment, youth often identified concerns controlled by teachers or administrators. Young people are also aware of and potentially influenced by negative adult behaviors (e.g., crime, drug use, alcohol abuse) (Ginsburg et al. 2002; Mahiri and Conner 2003; Towns 1996). As Towns (1996) found, youth tended to excuse negative behaviors displayed by adult relatives and instead attributed the behaviors to misfortunate circumstances. Therefore, by observing adults, youth can learn about the benefits and consequences of performing certain behaviors. Youth who are exposed to adults who smoke may acquire a smoking habit. Likewise, young people who are around adults who engage in prosocial behaviors are likely to exemplify similar behavior.

Youth empowerment, however, requires adults to be actively involved in fostering conditions and opportunities for youth to develop critical consciousness. Adults possess the authority to create safe environments and youth-centered conditions where young people feel welcomed and, therefore, are willing to share their views. In addition, adults have an increased access to institutions within the social environment that influence opportunities for children and adolescents to participate in decisions that affect their lives. The burden of the empowerment process, however, does not lie solely with youth or adults, but implies a shared co-learning relationship where both respective groups raise the level of collective critical consciousness.

\section{Participation Types}

Therefore, in essence, youth participation is the democratic practice of young people actively engaging with their social environment. The point of engagement can be initiated by three basic approaches: adult-driven, shared control, and youth-driven. The degree of control, however, can differ within these types. Thus, although research suggests that there are three basic types of participation, this typology includes two variations on adult-driven (i.e., Vessel and Symbolic) and youth-driven (i.e., Independent and Autonomous) participation to capture potential variation within these types.

The following description of the TYPE Pyramid presents details about each participation type by following the schematic, as presented in Fig. 4, from left to right. Discussion about the broader participation types (i.e., adultdriven, shared-control and youth-driven) is also presented alongside each of their respective sub-types.

\section{Adult-Driven Participation Types: Vessel and Symbolic}

Adult-driven participation can be described as activities developed by adults that are designed to engage youth. Some suggest adult-driven participation can result in manipulation, decoration or tokenism (Arnstein 1969; Guinier and Torres 2002; Hart 1992; Hogan 2002; Kreisberg 1992). Analysis provided by Guinier and Torres (2002) about race relations describes a parallel phenomenon. The authors suggest superficial racial diversity or tokenism can often occur because most strategies for social change ascribe to a hierarchical model of power over social relations. This power over context fosters an environment where-even among advocacy groups whose agendas are race-focused-those who are directly affected are not involved or their presence is merely decoration. As a result, dominant groups can maintain their power by pointing to the few examples of minority tokens present and not taking authentic steps towards egalitarianism. Furthermore, privilege may allow dominant groups to be unconscious of tokenism and how their power may operate to suppress others' needs. Among youth-adult relations, manipulation, decoration or tokenism can occur when the main objective of youth presence is to advance an adult-driven agenda. Youth participation in this scenario is merely aesthetic. Young people may be cognizant of this practice and, thus, skeptical of adult motivations (Zeldin 2004). When this happens, youth do not genuinely partake in planning activities, decision-making, or contributing their views. Instead, young people are present because it may be perceived as politically correct, project a particular image, or make an organization feel good. This, in effect, works counter to what adults may have originally intended and can serve to exacerbate social dynamics that disempower youth on a whole.

Conversely, one can argue that children benefit from a traditional pedagogical relationship with adults, especially when the objective is to teach specialized or technical skills 
(Larson et al. 2005). Several studies find positive outcomes when using an adult-driven approach to enhance youth development and prevent violence (e.g., Eccles and Gootman 2002; Fields and McNamara 2003; Hudson et al. 2006; Roth and Brooks-Gunn 2003). Larson et al. (2005) conducted a qualitative evaluation of different youth-adult partnership programs for high school youth. Although youth in the adult-driven programs had little or no input in the development of program activities, they still demonstrated benefits. In a theater program, youth acquired production skills such as mastering voice projection, ad-lib, and sewing techniques in addition to gaining self-confidence and socio-emotional growth. Similarly, youth in an adult-driven art program learned skills in planning and executing a large project, painting techniques, and professional etiquette in the art world. The researchers suggest that the characteristics and approach of the adults such as care, empathy, and use of open dialogue contributed to positive outcomes.

Despite potential benefits, May (1972) describes the underlying intention of this type of relationship as nutrient power. Nutrient power is power for the other; it essentially entails a helping relationship. Common examples of nutrient power dynamics are those relationships that are between parent and child, teacher and students, and therapist and patient. Labonte (in Bernstein et al. 1994) argues that a helping relationship is inherently one of power over. A power over dynamic can potentially undermine any initial well-meaning intentions. The unbalanced distribution of authority in many youth-adult nutrient arrangements inevitably challenges initial intentions because relations, whether subtle or not, operate within a context of one possessing more authoritative power over the other.

Nutrient power is demonstrated in findings from Hogan's (2002) ethnographic study of an adult-driven service-learning project. The project was designed to enhance youth development and participation; however, Hogan found that adult authority unintentionally and, in some cases intentionally, limited youth participation. Power dynamics between the service learning teacher and high school students created a space where the teacher's ideas were dominant. Although unintentional, the teacher used his authority to steer the discussion towards his expertise and gave long critical reflections when students did contribute. Hogan observed that the students would whisper among themselves, but largely refrained from sharing their views with the teacher, even when prodded. In another instance, students were asked to design and conduct a community survey, but the site's executive director overrode their efforts by presenting his own survey to the board and did not involve youth in any subsequent discussion. Youth expressed frustration and felt that their contributions were meaningless. Although the service- learning project was well intended, both the teacher and site director were limited by occupational obligations and were not able to break from their conventional roles enough to involve the students in participation at an adequate level to be meaningful.

Adult-driven participation has potential to be both beneficial and detrimental to youth development. As research suggests, the approach and characteristics of adults involved can help determine the degree to which youth benefit from participating (Camino 2000, 2005; Hogan 2002; Larson et al. 2005). Adults who listen to and address young people's needs are likely to observe more involvement and positive developmental outcomes than adults who choose to exercise their authority over youth. Thus, the spectrum of adult-driven participation encompasses a range between adults who have full control over decision-making to adults who listen to youth perspectives but ultimately make final decisions. These participation types are respectively labeled Vessel and Symbolic.

\section{Vessel}

This participation type describes a traditional youth-adult relationship that is adult-driven, demanding little to no input from young people. The term vessel draws upon Freire's (1970/2003) writings on power and pedagogy. Freire describes the traditional pedagogical relationship as banking education, where the teacher's task is to fill the students-who are seen as empty vessels-with his or her narration. Under these circumstances, teachers are the trained experts with authority; learning and development are mediated by adult-determined lessons and agendas. It is suggested that a banking education approach promotes a dominant power hierarchy where students may become overly dependent on teacher authority, therefore, spoiling potential for critical epistemic reflection (Hart et al. 1997; Kreisberg 1992). This youth-adult participation type is not only observed in learning environments but is also commonly found in the development of research and policy on children and adolescents, juvenile legal systems, and youth social services (Camino 2005; Hart et al. 1997; Larson et al. 2005; Meucci and Redmon 1997).

Due to a lack of youth involvement, the Vessel participation type has low empowerment potential. Although youth may be able to learn skills and acquire useful knowledge, little opportunity exists for young people to contribute their own ideas. In effect, this limits potential for co-learning with adults towards critical consciousness or awareness, a key part of the empowerment process. Critical consciousness is gained through an open dialogical practice where both adults and youth contribute their perspectives to develop an authentic understanding of the environment. Once critical consciousness is gained, action can be taken 
to strengthen assets or address concerns. Young peoples' critical consciousness and motivation to participate, however, may be hindered when youth voice is not actively encouraged, and they are not involved in planning and decision-making. When youth participation is this low, opportunities to build on strengths like self-efficacy, or to develop skills like problem solving are limited.

\section{Symbolic}

More recent efforts have been geared towards increasing participation and engaging youth in action and research (Checkoway and Gutierrez 2006). Many of these efforts can be classified as Symbolic participation. In this type of participation, youth have the opportunity to voice their perspectives about problems and their potential solutions, and be heard by decision-makers. Adults may, for example, set up formal or informal structures for youth to express their opinions and experiences. Youth positions on organizational boards, advisory committees, research projects, and in advocacy work often fall into this participation type. The participation arrangement is symbolic or representative of democratic processes; however, in the end, youth often do not have much power in the decision-making or agenda setting process.

Symbolic participation differs from Vessel participation by including youth voice. Youth voice requires a degree of critical awareness on the part of young people. By voicing their perspectives, youth have the opportunity to practice critical thinking by formulating opinions about problems and solutions. This practice encourages the development of competence, self-efficacy and mastery-all of which are key factors in positive youth development (Benson 1997) and psychological empowerment (Zimmerman 1995). Findings in youth voice research also suggest that, when asked, youth may have different ideas about their environments compared to adults (Mahiri and Conner 2003; Morrill et al. 2000; Zimmerman et al. 2004). This difference may be attributed to youth-adult segregation. Morrill et al. (2000), for example, found adults were largely absent as main characters when they asked youth to write about conflict in their lives. Yet, the influence of adult-driven institutions and discourse (e.g., media) were evident in almost all the stories. Youth, as a result, expressed being influenced by adult-driven institutional forces, but lacked the daily interaction they may have needed from positive adult role models to guide them towards healthy development.

Adults also can be the gatekeepers for how youth experience their environments. The intentions of adults, however well meaning, may be undermined by their greater control over decision-making or nutrient power dynamics. In the Symbolic participation type, youth may experience frustration over being able to voice their perspectives, but not possessing any control over decisions that will determine subsequent outcomes. This frustration can reduce youth access to control and limits empowerment potential.

\section{Youth-Adult Shared Control Participation Type:} Pluralistic

A field examining the empowerment and wellness potential of youth-adult partnerships is emerging (Jennings et al. 2006). Researchers suggest that the process of youth and adults working together can provide optimal conditions for youth empowerment and positive youth development (Foster-Fishman et al. 2005; Wallerstein et al. 2002; Wilson et al. 2006). Adults can serve as role models, sources of support and social capital, and primary sources of positive reinforcement when they collaborate with youth to share decision-making and planning activities. Shared control occurs as a transactional process between adults and youth, and is a key component in youth empowerment conceptual models (Chinman and Linney 1998; Jennings et al. 2006; Kim et al. 1998; Wallerstein et al. 2002).

Based on a community sample of youth $(\mathrm{n}=123 ; 12$ 19 year olds) and adults $(n=7)$, Cargo et al. (2004) describe this transaction as consisting of both adult and youth subprocesses. The adult subprocess occurs when adults create an empowering environment by providing a welcoming climate and enabling youth. For youth, the subprocess occurs through factors that encourage positive development and empowerment such as self-actualization, being engaged with others, and participating in decisionmaking and subsequent constructive change. The transactional process is cyclical and occurs through multiple feedback loops for both youth and adults to share control.

Shared control, however, does not necessarily translate to every decision and activity requiring equal youth and adult participation-i.e., both groups can jointly decide that adults may be better at making specific decisions or vice versa. Often, it is more appropriate for youth and adults to take on tasks and responsibilities that utilize their respective strengths (Libby et al. 2005). It may, for example, be advantageous for youth to brainstorm new ideas and adults to recommend a timeline and procedure for carrying out the ideas. In this situation, youth might come up with ideas that adults may not have considered whereas adults can draw upon experience to suggest how long the idea will take to implement, strategies for implementation and where to find resources.

Hart et al. (1997) suggest the degree and type of responsibilities assigned to both youth and adults may vary depending on the developmental needs of the young people involved. Middle school aged young people, for example, have different developmental needs for identity formation 
than elementary school aged youth. In general, children (i.e., 8-11 year olds) tend to adopt an external approach to their identity development, whereas, early adolescents (i.e., 12-14 year olds) are more inward-focused and philosophical. Furthermore, group membership serves a different function in identity development for children and adolescents. For children, social groups provide a space where they can demonstrate competence, independence and selfworth. For youth who are older than twelve, social interaction in group settings serve as a staging ground for experimentation with and merging of different ego identities. Although social interaction is still influential on identity formation for adolescents, at this later stage, their understanding of self is more intrapersonal than in earlier years. This more inward notion of self in later years may be attributed to advances in cognitive development. The ability to critically reason and grasp abstract concepts is not developed fully until mid- to late adolescence (Millstein and Litt 1993). Thus, considerations on the type of planning, decisions and activities that youth and adults decide to undertake may depend on the ages and cognitive capacities of the young people involved. Early adolescents may be more adept at taking on tasks by themselves whereas children may benefit from more adult involvement. For optimal youth development and empowerment, decisions about the degree and types of responsibilities taken on by youth and adults ought to be negotiated by both groups with a clear understanding of the rationale.

The pluralistic participation type recognizes the strengths of both youth and adults working in partnership to create and sustain both healthy youth and community development. In this type, the relationship between youth and adults is reciprocal. That is, youth and adults share planning and decision-making responsibilities to achieve goals. As partners, youth can offer creativity, a fresh perspective, willingness to try new ideas, and a youth-centered understanding of themselves and their peers, whereas adults can contribute experience, expertise on planning, decision-making and evaluation practices, and knowledge about community history, lessons learned and best practices (Libby et al. 2005).

Although youth-adult partnerships may have varying degrees of youth and adult control within them, shared planning and decision-making is what differentiates the pluralistic type from other participation types in the pyramid. The shared control between youth and adults provides a social arrangement that is ideal for positive youth development and empowerment. In this type, adults are involved at a level where the purpose of their presence is to maximize conditions and opportunities for youth to engage in pro-social activities, yet are not overly dominant or under-involved to a point where they hinder youth development or empowerment. Furthermore, youth and adult partnerships may have more empowerment potential when they are designed to both foster healthy youth development and also aim for positive organizational or community change (Schulz et al. 1995).

Researchers, for example, are beginning to examine the potential developmental benefits of youth participating in organizational and community decision-making. Although many of the studies on this topic are exploratory (e.g., Breitbart 1995; Finn and Checkoway 1998; Zeldin 2004), some researchers have been able to systematically link youth participation in decision-making to positive adolescent and community developmental outcomes. Among studies that examine youth participation in organizational governance (i.e., youth-adult partnerships that govern an organization), researchers find that youth demonstrate increased competence, acquire knowledge and practical skills, and strengthen ties to their communities (Checkoway et al. 2005; Mandel and Qazilbash 2005; Mitra 2004, 2005, 2006; Zeldin 2004). In an evaluation of eight youthadult organizational partnerships, Zeldin (2004) found that 16 youth (i.e., 14-20 year olds) reported an increased sense of agency and acquisition of practical skills, such as effective communication strategies, group facilitation, planning and management. Youth also connected with influential community leaders and displayed leadership by raising awareness about civic issues. Similarly, Mitra (2004) observed that high school students who were included in school-wide policy setting built stronger relationships with faculty and expressed an increased sense of school belonging compared to students who participated in peer-to-peer programming. Thus, youth-adult partnership research is beginning to suggest that Pluralistic type participation may be ideal for both empowering youth and community development.

\section{Youth-Driven Participation Types: Independent and Autonomous}

Participation in activities and organizations governed by youth can be thought of as youth-driven participation. This type of participation can by initiated by young people or adults, but it is youth who serve as the major decision makers. By making major decisions, youth can experience ownership over the agenda, become invested in outcomes and have opportunities to draw upon leadership skills (Larson et al. 2005). A common rationale for adults who initiate youth-driven participation is that youth are valuable resources capable of meaningful contributions (Camino 2000, 2005; Larson et al. 2005). This rationale also includes the perspective that the uneven power differential between youth and adults will impede potential for youth empowerment by rendering youth apathetic. Thus, the adult-initiated youth-driven approach is often predicated on 
the notion that to eliminate the power differential adults need to give up their power so that youth may gain power (Camino 2005).

A major assumption of this rationale is that power is a zero-sum phenomenon. That is, power is power over, it exists in limited supply and can only be gained if it is taken or another gives it up (Kreisberg 1992). Yet, researchers find when adults cede power to youth it may have unintended negative effects. In a youth-driven day camp, Larson et al. (2005) found that youth initially were able to brainstorm ideas for activities with ease, but due to inexperience, they struggled when it came to organizing and implementing the activities. As a result, their planning stalled; attendance at meetings diminished and the youth expressed disappointment in the end. It was not until adult advisors gave input when the youth were able to resolve internal conflicts and resume planning. Similarly, Camino (2005) found youth and adults had differing perspectives in a youth-driven empowerment program. Adults ranked their own cohesiveness and productivity with the group as high, whereas youth ranked them as low. In an effort to give youth control, the adults attended meetings but rarely gave input. This limited what the youth could learn from adults, hindered group effectiveness, and led to the young people feeling frustrated and abandoned. Similar potential also exists when youth-driven participation is youth-initiated. Although youth can be viewed as competent and capable, many lack experience with organizational decision-making and technical skills. Deficient skills, coupled with a lack of guidance, may lead to poor organizational outcomes and youth feelings of inadequacy.

\section{Independent}

As a response to traditional Vessel youth participation types, some adults have taken the approach that they must give up their power for youth to gain power. Adults will, for instance, create a space or make resources available for youth to conceptualize and implement their own programming. Although this approach has been recognized for enhancing youth independence, it has also been criticized for lack of adult involvement (Camino 2005; Larson et al. 2005). Young people, for example, may have plenty of creative ideas for programming, but may lack expertise on how to develop and implement a strategic plan. Youth who are left to their own devices miss out on the skills and experience that adults can bring to the table.

The empowerment potential within this type is not as optimal as in the Pluralistic type, because youth are provided with limited guidance. Although youth in the Independent type may have significant opportunities for active participation, they might take longer to successfully implement their ideas due to lack of skills, which could lead to frustration. Young people may also not be aware of or connected to resources that could make their planning and activities more efficient. Furthermore, when adults step aside with the intention to empower youth, they could inadvertently alienate them instead. Nevertheless, the practice of organizing, planning, and controlling major decision-making can build skills and contribute to increased competence, critical awareness, and self-efficacy.

\section{Autonomous}

The Autonomous participation type describes scenarios where youth have taken measures to create their own spaces for voice, participation and expression of power regardless of adult involvement. This type of youth participation operates without consent or guidance from adults. Youth may create spaces to address their own needs - which can potentially be empowering-but without adult guidance these spaces can potentially be detrimental for healthy development. Oppositional youth culture such as youth gangs can illustrate how this type of participation may impede positive youth development and participation. Young people in gangs might organize to develop independence from adults, gain a sense of cohesion, and participate in decision-making roles; however, the delinquent and criminal behavior associated with youth gang activities hinders positive development.

Although deviant behavior may not always be characteristic of an Autonomous participation type, empowerment potential is still limited because youth may not make vital connections to supportive adults who can help create opportunities, secure resources and provide experienced guidance. In addition to a diminished sense of empowerment youth may feel from having not yet acquired certain skills, young people in the Autonomous type of participation also may not be able to benefit from the knowledge adults can possess about community or organizational history, best practices and lessons learned. In this case, the opportunity to pass along intergenerational memory is lost, diminishing young people's abilities to connect their circumstances to the historical narratives of their communities. This youth-adult segregation can disempower and stunt the development of both youth and communities.

\section{Implications and Conclusion}

The TYPE Pyramid identifies five distinct types of youth participation; however, all youth-adult arrangements may not be easily categorized into one type. It is possible for a research, organizational, or programmatic approach to be classified as a combination of types. A program might, for example, begin with a Vessel approach and evolve into a 
Symbolic type. Research projects and organizations could also have various stages and processes that fit into different types of youth-adult participation. Thus, the TYPE Pyramid is not designed to be a rigid framework, but rather used as a heuristic device to challenge investigators, practitioners, and youth alike when developing research projects and youth programs.

The TYPE Pyramid also does not illustrate how older youth can serve as an intermediary between younger adolescents and adults; thus, partnerships can serve as a pipeline that cuts across multiple generational age groups. These pipeline partnerships have potential to be empowering for both those individuals that are involved and the larger community. In addition, the pyramid may not adequately delineate significant developmental distinctions. That is, children and younger adolescents may benefit more from the increased adult involvement found in adult-driven participation types whereas older adolescents may derive more developmental benefits from the youth-driven types. In some cases, younger children may be less prepared cognitively and emotionally to share equal responsibility with adults. It is, however, recognized that theories about developmental capacities at various life stages are often socially and culturally bound (Hill and Fortenberry 1992; Punch 2002). Therefore, socio-cultural expectations of childhood and adolescence may have more bearing on the capacity to achieve a pluralistic participation type than actual innate cognitive abilities.

Although the pyramid may have limited explanatory potential for various developmental stages among children and adolescents, methods that align with PAR principles may help youth-adult partnerships overcome this barrier. Researchers have identified a range of techniques for engaging both youth and adults of diverse backgrounds, ages, and abilities that include visual methods (e.g., drawings, photographs, and video), diaries, vignettes, and role-playing (Driskell 2002; Hill 1997; Punch 2002). Photovoice is a specific example of a PAR method that has been used to enhance empowerment with middle school aged youth in a youth-adult partnership that focuses on violence prevention (Franzen et al., 2009). As a participatory documentary photography method rooted in Frierian principles of empowerment and co-learning (Wang and Burris 1997), the contributions of researchers and participants are equally valued in this approach. The method is highly dependent on visuals rather than literacy, which can assist in leveling the power differential between adult researchers and young participants. Basic photography skills are necessary to apply Photovoice successfully, thus, the ability level of both children and adults ought to be considered. Younger children may have difficulty working with complicated cameras that require an advanced understanding of photography techniques. On the other hand, some older adults may not be as comfortable with the newer technology found in digital cameras when compared to younger people. In this scenario, a joint youth-adult decision on which cameras should be used can enhance the efficacy of the project. As such, the co-learning aspects of PAR methods have critical implications for how power is balanced within a partnership between youth and adults. The argument can be made that if careful context appropriate methods (i.e., approaches, techniques, and tasks) are applied, a pluralistic participation type can be achieved regardless of developmental age.

Another issue to consider is that communities of color, impoverished, urban, and rural communities may face several barriers that can impede establishing higher levels of youth participation. African American, Latino, urban, and impoverished communities are disproportionately affected by violence. The violence and crime that afflicts some of these neighborhoods may not readily lend themselves to be safe spaces for participatory youth research and community action intervention. In this context, beginning youth-adult partnerships requires a critical mass of dedicated adults to reclaim public spaces for safe youth involvement. Adults who work towards reclaiming these spaces need to consider that the process warrants time for community buy-in, gaining trust, and building relationships. Many impoverished, urban, and rural youth are also challenged by economic divestment in their communities. Resources may not be available to provide the financial and human capital to build youth and adult partnerships. In addition, low-income youth may be burdened with extra responsibilities their higher income counterparts may not face such as working and taking care of siblings. These extra responsibilities allow little free time and perhaps energy for increased participation. Furthermore, researchers interested in involving low-income and youth of color need to be critically aware of how nutrient power dynamics may impede the trust building process. Despite these barriers, past research suggests that youth in these types of communities want to be more involved in participatory action and research with adult guidance (Fine et al. 2003; Ginsburg et al. 2002). The TYPE Pyramid can assist interested youth and adults alike in determining which participation type may best suit their context.

As previously suggested, practitioners, researchers, and youth may find the pyramid typology most useful as a heuristic device. Future efforts may further explore practical application of the model. One approach that aligns with TYPE Pyramid is PAR. Both the typology and PAR projects with children emphasize increasing youth opportunities to participate in decisions that influence their lives. In effect, by valuing participation, empowerment and action, a PAR approach does not view research as separate 
from practice (Penuel and Freeman 1997). Treseder's (1997) practice-based guide may be a useful resource for PAR researchers interested in forming youth-adult partnerships for empowerment. Although Treseder suggests his manual was developed for children 8 years of age or older, he also recommends that Miller's (2003), Never Too Young: How Young People Can Take Responsibility and Make Decisions, can be applied with younger children. Yet, despite increased interest on this topic in the practicebased and conceptual literature, few empirical studies on PAR with children exist. Expanding research on PAR with children may elucidate the practical and theoretical parameters of the pyramid typology.

Furthermore, youth-adult partnerships in both organizations and participatory action research warrant further study. Although current trends suggest these partnerships are creating opportunities for positive youth development and empowerment, researchers still have a limited understanding of what core elements are necessary to make youth-adult partnerships successful. Understanding the core elements of Pluralistic youth-adult partnerships may help reveal how resources can be directed towards improving youth participation, positive youth development, and empowerment.

Another area of research to explore is expanding upon the typology's functions. The typology, for example, could be used to guide the design of a participatory evaluation tool. Measurable items could be created to assess each participation type. Youth-adult partnerships, for example, that aim to either reach or maintain a certain participation type could use the tool to assess participation status. This may be one way for adult researchers, practitioners, policy makers and youth to begin building towards ideal youthadult partnerships.

In conclusion, the TYPE Pyramid was designed to contribute a framework for understanding different ways young people and adults can interact and how this interaction affects youth and eventually community development. The pyramid was also designed with child and adolescent health promotion in mind. By combining the health promoting approaches of both empowerment and positive youth development, the TYPE Pyramid delineates what participation types may be most useful at enhancing the strengths of young people rather than focusing on problems. The participation types reveal where youth voices are valued and their contributions can be most meaningful.

Acknowledgments This paper was supported by the CDC/ASPH/ PRC Minority Fellowship, the W. K. Kellogg Fellowship in Health Policy Research, the Center for Research on Ethnicity, Culture and Health and the Rackham Merit Fellowship. The paper does not necessarily reflect the views of the aforementioned funding sources.

\section{References}

Arnstein, S. (1969). A ladder of citizen participation. Journal of American Institute of Planners, 35(4), 216-224.

Bandura, A. (1977). Social learning theory. Englewood Cliffs, NJ: Prentice Hall.

Bennett, S., Coggan, C., \& Adams, P. (2003). Problematising depression, young people, mental health and suicidal behaviors. Social Science and Medicine, 57(2), 289-299.

Benson, P. L. (1997). All kids are our kids: What communities must do to raise caring and responsible children and adolescents. San Francisco: Jossey-Bass.

Bernstein, E., Wallerstein, N., Braithwaite, R., Gutierrez, L., Labonte, R., \& Zimmerman, M. A. (1994). Empowerment forum-A dialog between guest editorial-board members. Health Education Quarterly, 21(3), 281-294.

Breitbart, M. M. (1995). Banners for the street: Reclaiming space and designing change with urban youth. Journal of Planning Education and Research, 15, 35-49.

Brookmeyer, K. A., Henrich, C. C., \& Schwab-Stone, M. (2005). Adolescents who witness community violence: Can parent support and prosocial cognitions protect them from committing violence? Child Development, 76(4), 917-929.

Camino, L. A. (2000). Youth-adult partnerships: Entering new territory in community work and research. Applied Developmental Science, 4(Suppl. 1), 11-20.

Camino, L. A. (2005). Pitfalls and promising practices of youth-adult partnerships: An evaluator's reflections. Journal of Community Psychology, 33(1), 75-85.

Cargo, M., Grams, G. D., Ottoson, J. M., Ward, P., \& Green, L. W. (2004). Empowerment as fostering positive youth development and citizenship. American Journal of Health Behavior, 27(Suppl 1), S66-S79.

Checkoway, B., Allison, T., \& Montoya, C. (2005). Youth participation in public policy at the municipal level. Children and Youth Services Review, 27(10), 1149-1162.

Checkoway, B. N., \& Gutierrez, L. M. (Eds.). (2006). Youth participation and community change. New York: The Hayworth Press.

Chinman, M. J., \& Linney, J. A. (1998). Toward a model of adolescent empowerment: Theoretical and empirical evidence. The Journal of Primary Prevention, 18(4), 393-413.

Cornwall, A. (2008). Unpacking 'participation': Models, meanings, and practices. Community Development Journal, 43(3), 269283.

Cornwall, A., \& Jewkes, R. (1995). What is participatory research? Social Science and Medicine, 41(12), 1667-1676.

Daiute, C., \& Fine, M. (2003). Youth perspectives on violence and injustice. Journal of Social Issues, 59(1), 1-14.

Driskell, D. (2002). Creating better cities with children and youth: A manual for participation. Paris: UNESCO.

Eccles, J. S., \& Gootman, J. A. (2002). Community programs to promote youth development. Washington, DC: National Academy Press.

Fauth, R. C., Roth, J. L., \& Brooks-Gunn, J. (2007). Does the neighborhood context alter the link between youth's after-school time activities and developmental outcomes? A multilevel analysis. Developmental Psychology, 43(3), 760-777.

Fields, S. A., \& McNamara, J. R. (2003). The prevention of child and adolescent violence. Aggression and Violent Behavior, 8, 61-91.

Fine, M., Freudenberg, N., Payne, Y., Perkins, T., Smith, K., \& Wanzer, K. (2003). "Anything can happen with police around": Urban youth evaluate strategies of surveillance in public places. Journal of Social Issues, 59(1), 141-158. 
Finn, J., \& Checkoway, B. N. (1998). Young people as competent community builders: A challenge to social work. Social Work, 43(4), 335-345.

Florin, P., \& Wandersman, A. (1990). An introduction to citizen participation, voluntary organizations, and community development: Insights for empowerment through research. American Journal of Community Psychology, 18(1), 41-54.

Fogel, S. J. (2004). Risks and opportunities for success: Perceptions of urban youths in a distressed community and lessons for adults. Families in Society, 85(3), 335-344.

Foster-Fishman, P., Deacon, Z., Nievar, M. A., \& McCann, P. (2005). Using methods that matter: The impact of reflection, dialogue and voice. American Journal of Community Psychology, 36(3/4), 275-291.

Franzen, S., Morrel-Samuels, S., Reischl, T. M., \& Zimmerman, M. A. (2009). Using process evaluation to strengthen intergenerational partnerships in the youth empowerment solutions program. Journal of Prevention \& Intervention in the Community, 37(4), 289-301.

Freire, P. (1970/2003). Pedagogy of the oppressed (30th Ed.). New York: Continuum.

Furstenberg, F. F. (2000). The sociology of adolescence and youth in the 1990s: A critical commentary. Journal of Marriage and the Family, 62, 896-910.

Ginsburg, K. R., Alexander, P. M., Hunt, J., Sullivan, M., \& Cnaan, A. (2002). Enhancing their likelihood for a positive future: Focus groups reveal the voice of inner-city youth. Pediatrics, 109(6), 95.

Guinier, L., \& Torres, G. (2002). Rethinking conventions of zero-sum power. The miner's canary: Enlisting race, resisting power, transforming democracy (pp. 108-130). Cambridge, MA: Harvard University Press.

Hart, R. (1992). Children's participation: From tokenism to citizenship (no. 4). Florence, Italy: UNICEF International Child Development Centre.

Hart, R., Dauite, C., Iltus, S., Kritt, D., Rome, M., \& Sabo, K. (1997). Developmental theory and children's participation in community organizations. Social Justice, 24(3), 33-63.

Hill, M. (1997). Participatory research with children. Child and Family Social Work, 2, 171-183.

Hill, R. F., \& Fortenberry, D. J. (1992). Adolescence as a culture bound syndrome. Social Science and Medicine, 35, 73-80.

Hogan, K. (2002). Pitfalls of community-based learning: How power dynamics limit adolescents' trajectories of growth and participation. Teachers College Record, 104(3), 586-624.

Hudson, D., Zimmerman, M. A., \& Morrel-Samuels, S. (2006). Youth violence prevention: Theory and practice. In A. C. Gielen, D. A. Sleet, \& R. J. DiClemente (Eds.), Injury and violence prevention: Behavioral science theories, methods, and applications (pp. 368-392). San Francisco: Jossey-Bass.

Jarrett, R. L., Sullivan, P. J., \& Watkins, N. D. (2005). Developing social capital through participation in organized youth programs: Qualitative insights from three programs. Journal of Community Psychology, 33(1), 41-55.

Jennings, L. B., Parra-Medina, D. M., Messias, D. K., \& McLoughlin, K. (2006). Toward a critical social theory of youth empowerment. Journal of Community Practice, 14(1/2), 31-55.

Kim, S., Crutchfield, C., Williams, C., \& Hepler, N. (1998). Toward a new paradigm in substance abuse and other problem behavior prevention for youth: Youth development and empowerment approach. Journal of Drug Education, 28(1), 1-17.

Kreisberg, S. (1992). Transforming power: Domination, empowerment and education. Albany, NY: State University of New York Press.

Larson, R., Walker, K., \& Pearce, N. (2005). A comparison of youthdriven and adult-driven youth programs: Balancing inputs from youth and adults. Journal of Community Psychology, 33(1), $57-74$.

Lerner, R. M., Almerigi, J. B., Theokas, C., \& Lerner, J. V. (2005). Positive youth development-A view of the issues. Journal of Early Adolescence, 25(1), 10-16.

Libby, M., Rosen, M., \& Sedonaen, M. (2005). Building youth-adult partnerships for community change: Lessons from the youth leadership institute. Journal of Community Psychology, 33(1), $111-120$.

Mahiri, J., \& Conner, E. (2003). Black youth violence has a bad rap. Journal of Social Issues, 59(1), 121-140.

Mandel, L. A., \& Qazilbash, J. (2005). Youth voices as change agents: Moving beyond the medical model in school-based health center practice. Journal of School Health, 75(7), 239-242.

May, R. (1972). Power and innocence. New York: Norton.

McHale, S. M., Crouther, A. C., \& Tucker, C. J. (2001). Free-time activities in middle childhood: Links with adjustment in early adolescence. Child Development, 72(6), 1764-1778.

Meucci, S., \& Redmon, J. (1997). Safe spaces: California children enter a policy debate. Social Justice, 24(3), 139-151.

Miller, J. (2003). Never too young: How young people can take responsibility and make decisions. London: Save the Children.

Millstein, S. G., \& Litt, I. F. (1993). Adolescent health. In S. Feldman \& G. Elliot (Eds.), At the threshold: The developing sdolescent (pp. 431-456). Cambridge, MA: Harvard University Press.

Millstein, S. G., Petersen, A. C., \& Nightingale, E. O. (1993). Adolescent health promotion: Rationale, goals, and objectives. In S. G. Millstein, A. C. Petersen, \& E. O. Nightingale (Eds.), Promoting the health of adolescents: New directions for the twenty-first century (pp. 3-10). New York: Oxford University Press.

Minkler, M. (2000). Using participatory action research to build healthy communities. Public Health Reports, 115(2/3), 191-197.

Minkler, M., \& Cox, K. (1980). Creating critical consciousness in health: Applications of Freire's philosophy and methods to the health care setting. International Journal of Health Services, $10(2), 311-322$.

Mitra, D. L. (2004). The significance of students: Can increasing "student voice" in schools lead to gains in youth development? Teachers College Record, 106(4), 651-688.

Morrill, C., Yalda, C., Adelman, M., Musheno, M., \& Bejarano, C. (2000). Telling tales in school: Youth culture and conflict narratives. Law \& Society Review, 34(3), 521-565.

Muuss, R. E. (1962/1996). G. Stanley Hall's biogenetic psychology of adolescence. Theories of adolescence (6th Ed., pp. 15-17). New York, NY: McGraw-Hill.

Penuel, W., \& Freeman, T. (1997). Participatory action research in youth programming: A theory in use. Child \& Youth Care Forum, 26(3), 175-185.

Phelan, P., Locke, A., \& Cao, H. T. (1992). Speaking up: Students' perspectives on school. Phi Delta Kappan, 73(9), 695-704.

Pretty, J. N. (1995). Participatory learning for sustainable agriculture. World Development, 23(8), 1247-1263.

Price, R. H. (1990). Wither participation and empowerment? American Journal of Community Psychology, 18(1), 163-167.

Punch, S. (2002). Research with children: The same or different from research with adults? Childhood, 9, 321-341.

Rappaport, J. (1995). Empowerment meets narrative: Listening to stories and creating settings. American Journal of Community Psychology, 23(5), 795.

Richardson, R. A. (2004). Early adolescence talking points: Questions that middle school students want to ask their parents. Family Relations, 53(1), 87-94.

Rocha, E. M. (1997). A ladder of empowerment. Journal of Planning Research, 17, 31-44. 
Roth, J. L., \& Brooks-Gunn, J. (2003). Youth development programs: Risk, prevention and policy. Journal of Adolescent Health, 32(3), 170-182.

Schulz, A. J., Israel, B. A., Zimmerman, M. A., \& Checkoway, B. N. (1995). Empowerment as a multi-level construct: Perceived control at the individual, organizational and community levels. Health Education Research, 10(3), 309-327.

Shier, H. (2001). Pathways to participation: Openings, opportunities, and obligations. Children and Society, 15, 107-117.

Tarver, D. T., Wong, N. T., Neighbors, H. W., \& Zimmerman, M. A. (2004). The role of father support in the prediction of suicidal ideation among black adolescent males. In N. Way \& J. Y. Chu (Eds.), Adolescent boys: Exploring diverse cultures of boyhood (144 pp.). New York: New York University Press.

Towns, D. P. (1996). "Rewind the world!": An ethnographic study of inner-city African-American children's perceptions of violence. The Journal of Negro Education, 65(3), 375-389.

Treseder, P. (1997). Empowering children \& young people: Promoting involvement in decision-making. London: Save the Children.

Wallerstein, N. (1992). Powerlessness, empowerment, and health: Implications for health promotion programs. American Journal of Health Promotion, 6(3), 197-205.

Wallerstein, N., \& Bernstein, E. (1988). Empowerment educationFreire's ideas adapted to health-education. Health Education Quarterly, 15(4), 379-394.

Wallerstein, N., Sanchez-Merki, V., \& Dow, L. (2002). Freirian praxis in health education and community organizing. In M. Minkler (Ed.), Community organizing and community building for health (pp. 195-211). New Brunswick, NJ: Rutgers University Press.

Wang, C., \& Burris, M. A. (1997). Photovoice: Concept, methodology, and use for participatory needs assessment. Health Education and Behavior, 24(3), 369.

White, S. (1996). Depoliticizing development: The uses and abuses of participation. Development in Practice, 6(1), 6-15.
Whitlock, J. (2007). The role of adults, public space and power in adolescent community connectedness. Journal of Community Psychology, 35, 499-518.

Willis, P. (1990). Common culture: Symbolic work at play in the everyday cultures of the young. London: Open University Press.

Wilson, N., Minkler, M., Dasho, S., Carrillo, R., Wallerstein, N., \& Garcia, D. (2006). Student facilitators and collaborative teams for participation: Training students as facilitators in the youth empowerment strategies (YES!) project. Journal of Community Practice, 14(1/2), 201-217.

Zeldin, S. (2004). Youth as agents of adult and community development: Mapping the process and outcomes of youth engaged in organizational governance. Applied Developmental Science, 8(2), 75-90.

Zeldin, S., Camino, L., \& Mook, C. (2005a). The adoption of innovation in youth organizations: Creating the conditions for youth-adult partnerships. Journal of Community Psychology, 33(1), 121-135.

Zeldin, S., Larson, R., Camino, L., \& O'Connor, C. (2005b). Intergenerational relationships and partnerships in community programs: Purpose, practice, and directions for research. Journal of Community Psychology, 33(1), 1-10.

Zimmerman, M. A. (1995). Psychological empowerment: Issues and illustrations. American Journal of Community Psychology, 23(5), 581-599.

Zimmerman, M. A. (2000). Empowerment theory: Psychological, organizational and community levels of analysis. In J. Rappaport \& E. Seidman (Eds.), Handbook of community psychology (pp. 43-63). New York, NY: Plenum Press.

Zimmerman, M. A., Morrel-Samuels, S., Wong, N., Tarver, D., Rabiah, D., \& White, S. (2004). Guns, gangs, and gossip: An analysis of student essays on youth violence. Journal of Early Adolescence, 24(4), 385-411.

Zimmerman, M. A., \& Warschausky, S. (1998). Empowerment theory for rehabilitation research: Conceptual and methodological issues. Rehabilitation Psychology, 43(1), 3-16. 